\title{
Capítulo 40
}

\section{INFLUÊNCIA DO PROCESSO DE TORREFAÇÃO NA CAPACIDADE ANTIOXIDANTE E NOS TEORES DE COMPOSTOS FENÓLICOS TOTAIS DE CAFÉ ARÁBICA (COFFEA ARABICA L.)}

DOI: $10.37423 / 200601512$

Raquel Bernardo Nana de Castro (Núcleo de Alimentos Funcionais, Escola de nutrição, Universidade Federal do estado do Rio de Janeiro (UNIRIO).

Júlia Montenegro (Núcleo de Alimentos Funcionais, Escola de nutrição, Universidade Federal do estado do Rio de Janeiro (UNIRIO).

Rodrigo Gonçalves Gusmão de Souza (Núcleo de Alimentos Funcionais, Escola de nutrição, Universidade Federal do estado do Rio de Janeiro (UNIRIO).

Isabela Porto Carrero (Núcleo de Alimentos Funcionais, Escola de nutrição, Universidade Federal do estado do Rio de Janeiro (UNIRIO).

Otniel Freitas Silva (Empresa Brasileira de Pesquisa Agropecuária-Embrapa Agroindústria de Alimentos, Rio de Janeiro

Anderson Junger Teodoro (Núcleo de Alimentos Funcionais, Escola de nutrição, Universidade Federal do estado do Rio de Janeiro (UNIRIO).

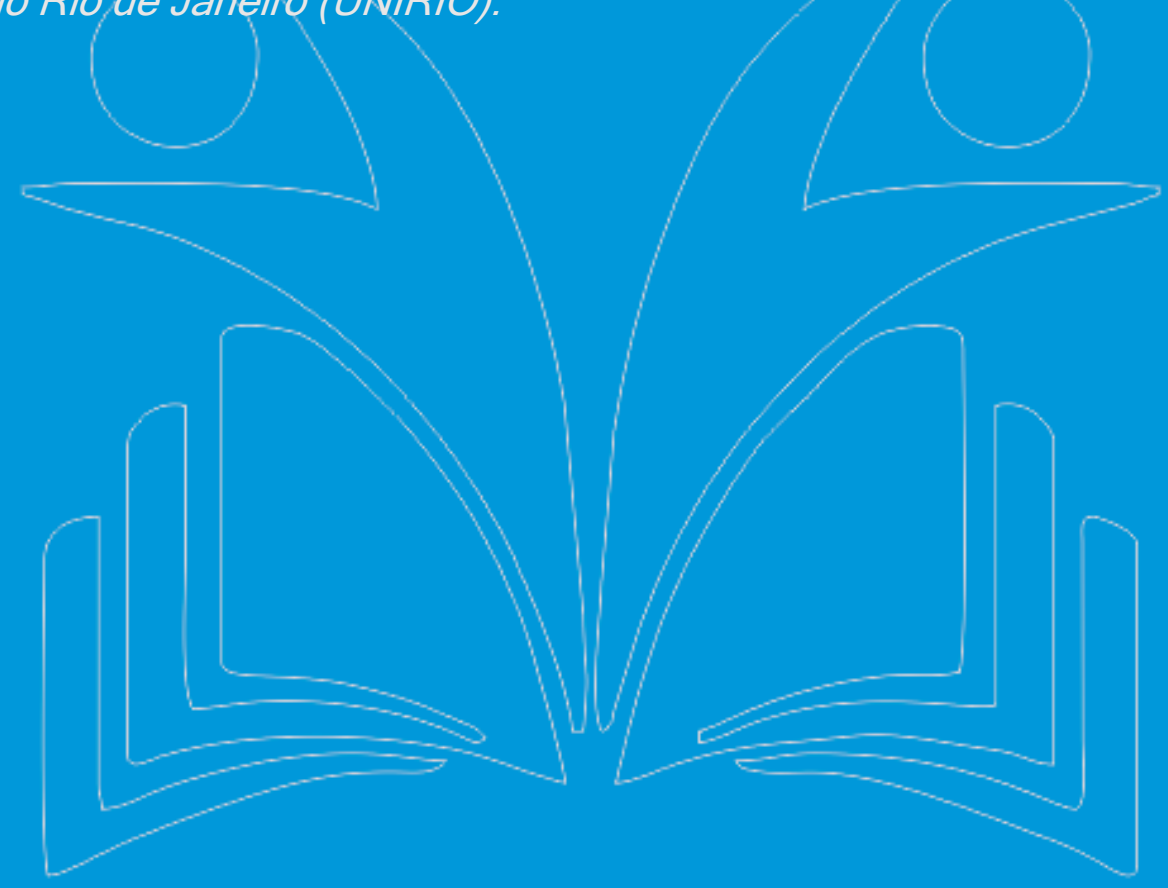


RESUMO: O café é amplamente consumido e possui compostos com efeitos benéficos para a saúde. Porém, o processo de torrefação afeta o conteúdo dos compostos bioativos e compostos indesejados podem ser formados. Assim, o objetivo do trabalho foi avaliar a atividade antioxidante e conteúdo de bioativos em diferentes níveis de torrefação de café. Os grãos verdes de Coffea arabica foram processados em torra clara, média, escura e italiana, sendo os compostos extraídos por fluido supercrítico. A capacidade antioxidante dessas amostras foi avaliada pelos métodos DPPH, ABTS, FRAP e ORAC. O teor total de compostos fenólicos totais foi analisado pelo método de Folin-Ciocalteu. A quantidade de cafeína e ácido clorogênico (5-CQA) foram determinados por cromatografia líquida de alta eficiência. Os extratos de café verde e torra clara apresentaram maior capacidade antioxidante. Os teores de compostos fenólicos e ácido clorogênico foram reduzidos significativamente pela ação do calor. O café verde e a torra clara apresentaram maior potencial bioativo sendo formas mais potencialmente benéficas para a saúde de utilização do café.

Palavras chave: café arábica, torrefação, antioxidante. 


\section{INTRODUÇÃO}

O café é a terceira bebida mais popular do mundo depois da água e do chá, sendo a segunda commodity mais negociada depois do petróleo. O café arábica é o café mais consumido no mundo, por seu sabor e aroma agradáveis (FARAH, 2012). O Brasil é o maior produtor e exportador de café e segundo maior consumidor da bebida no mundo (CONAB, 2018).

A composição química do café cru é influenciada pela variedade genética, condições ambientais como altitude, temperatura e umidade, e pelo processamento pós-colheita (DÚRAN, 2017). O grão do café (café verde) é composto principalmente de água, carboidratos e fibras, proteínas e aminoácidos livres, lipídios, minerais, ácidos orgânicos, ácidos clorogênicos, trigonelina e cafeína (FARAH, 2012). O café contém também ácidos clorogênicos, responsáveis por grande parte da atividade antioxidante da bebida, com potencial atividade antibacteriana, antiviral e anti-hipertensiva (NAVEED et al, 2018).

Porém, a infusão do café é um processo que produz alteração na composição química, principalmente após sua torrefação, onde compostos originais do grão são degradados e novos compostos são formados garantindo suas características de sabor e aroma (JUNG, 2017). Contudo, os teores de ácidos clorogênicos e de cafeína podem variar dependendo do processo de torrefação aplicado (DIAS; ORMAZA; ROJANO, 2017). O grão do café pode ser processado a diferentes níveis de torrefação, formando cafés de torra clara até cafés de torras mais escuras (FARAH, 2012).

As altas temperaturas observadas na torrefação levam à formação de material polimérico, ligando covalentemente os ácidos clorogênicos e outros componentes do café, como é o caso dos polissacarídeos e proteínas, podendo levar à formação de compostos castanhos de alto peso molecular denominados melanoidinas (NUNES; COIMBRA, 2001). As melanoidinas possuem atividade antioxidante, antimicrobiana e anti-hipertensiva (JIMENEZ-ZAMORA; PASTORIZA; RUFIÁN-HENAREZ, 2015) A acrilamida é subproduto da reação de Maillard, e é uma substância potencialmente prejudicial à saúde, visto que tem sido considerada neurotóxica e carcinogênica (PORTO et al., 2015).

Assim, o objetivo do presente trabalho foi analisar a capacidade antioxidante e o teor de compostos bioativos (compostos fenólicos, ácido clorogênico e cafeína) no café verde e em diferentes níveis de torra. 


\section{MATERIAL E MÉTODOS}

\section{MATÉRIA PRIMA}

Os grãos de Coffea arabica (café Arábica) foram adquiridos de regiões produtoras dos estados do Rio de Janeiro. Tais amostras foram transportadas e armazenadas no Laboratório de Diagnostico Molecular e Micologia da EMBRAPA Agroindústria de Alimentos, RJ.

As amostras de cafés foram processadas nas torras clara (12 minutos à $\left.230^{\circ} \mathrm{C}\right)$; média (14 minutos à $\left.240^{\circ} \mathrm{C}\right)$, escura $\left(15\right.$ minutos à $\left.245^{\circ} \mathrm{C}\right)$, e italiana $\left(23\right.$ minutos à $\left.250^{\circ} \mathrm{C}\right)$, realizadas no torrador Gene café ${ }^{\circledR}$. Estes níveis de torra são classificados de acordo com a Escala Agtron (RABELO, 2015).

\section{OBTENÇÃO DOS EXTRATOS DE CAFÉ POR CO 2 SUPERCRÍTICO}

Após a obtenção das amostras de café moído nas torras clara, média, escura e italiana, os extratos de café foram produzidos por método de extração por $\mathrm{CO}_{2}$ supercrítico, no Conjunto de Extração Supercrítica (modelo BR003F, Fornecedor: MAQNAGUA) no Serviço Nacional de Aprendizagem Industrial (SENAI) e foram padronizados para os experimentos de atividade biológica. Foram realizadas três repetições para os tratamentos descritos, os quais serão submetidas à todas as análises propostas.

Conforme metodologia descrita por Zetzl, Brunner e Meireles (2003), o vaso do reator, com volume interno de $1 \mathrm{~L}$, foi preenchido com $40 \mathrm{~g}$ de amostra de café arábica verde e café arábica submetido previamente a diferentes processos de torra. Em seguida, foram introduzidos no reator $200 \mathrm{~mL}$ de etanol. Posteriormente, o vaso foi aquecido até a temperatura de trabalho de 60 ㄷ C e, após a estabilização das condições do sistema, pressurizado com $\mathrm{CO}_{2}$ até a pressão de trabalho de 100 bar, com auxílio de bomba hidropneumática. A partir de então, foi esperado o tempo da estabilização das condições do sistema e 2 horas para contagem do tempo de residência do material no reator. Após o tempo estipulado, a pressão do sistema foi reduzida, $\mathrm{o} \mathrm{CO}_{2}$ foi pressurizado para retornar ao tanque de armazenamento e o extrato foi coletado via válvula agulha para um recipiente fechado, e armazenado a -8ํ em câmara fria.

\section{DETERMINAÇÃO DE COMPOSTOS FENÓLICOS TOTAIS}

A análise de fenólicos totais foi realizada de acordo com o ensaio de Folin-Ciocalteu, (SINGLETON et al., 1965). As alíquotas dos extratos supercríticos de café $(250,500$ e $1000 \mu \mathrm{L})$ foram pipetadas e repousaram ao abrigo da luz por duas horas e após esse período, foi realizado a leitura em 
espectrofotômetro na absorbância de $750 \mathrm{~nm}$. Os resultados foram comparados com a reação do padrão ácido gálico e expresso em mg de ácido gálico (GAE)/100g de amostra.

\section{CARACTERIZAÇÃO QUÍMICA DOS EXTRATOS DE CAFÉ POR HPLC}

As extrações da cafeína foram realizadas com água quente e clarificadas com soluções de Carrez (TRUGO; MACRAE, 1984). A determinação foi realizada por cromatografia líquida de alta eficiência (CLAE) de acordo com Farah et al. (2006).

Os ácidos clorogênicos foram extraídos com metanol aquoso (40\%) e clarificados com as soluções de Carrez. Em seguida os extratos foram analisados por CLAE de acordo com o método descrito por Farah et al. (2005). Para a determinação de cafeína o método usado foi baseado na extração das metilxantinas por ultrassom e fase móvel, posterior separação cromatográfica por CLAE com coluna C18 e fase móvel acetonitrila/ácido acético, utilizando detector PDA com extração a 280nm e método de padronização externa (PERRONE; DONANGELO; FARAH, 2008).

\section{AVALIAÇÃO DA ATIVIDADE SEQUESTRANTE DO RADICAL DPPH}

A medida da atividade sequestrante do radical DPPH foi realizada de acordo com a metodologia descrita por Brand-Williams \& Berset (1995). Para avaliação da atividade antioxidante, as amostras em três concentrações em triplicata foram adicionadas para reação com o radical estável DPPH em uma solução de metanol. A redução do radical do DPPH foi medida através da leitura da absorbância a 515 nm em 30 min de reação. Foi utilizado padrão de trolox (6-hidroxi-2,5,7,8-tetrametilcromo-2-ácido carboxílico) e a atividade antioxidante foi expressa em $\mu \mathrm{mol}$ de trolox por grama de amostra.

\section{ANÁLISE DETERMINAÇÃO DA ATIVIDADE ANTIOXIDANTE TOTAL PELO MÉTODO DE REDUÇÃO DO FERRO (FRAP)}

A atividade antioxidante pelo método de FRAP foi determinada de acordo com Rufino et al. (2006). Este método baseia-se na quantificação da capacidade de redução do complexo Fe(III)-TPTZ (cor azul clara) para o complexo Fe(II)-TPTZ (cor azul escura) em meio ácido, reação esta que é desencadeada pelo antioxidante presente na amostra. O método consiste em adicionar a $100 \mu \mathrm{L}$ da amostra e quantificar, em $2,7 \mathrm{~mL}$ de reagente FRAP somado a $270 \mu \mathrm{L}$ de água destilada. Após 30 minutos em banho-maria foi efetuada a leitura de absorbância a $595 \mathrm{~nm}$. A curva padrão foi produzida com uma solução de sulfato ferroso com quatro diluições diferentes. Os resultados foram expressos em $\mu \mathrm{M}$ de sulfato ferroso por grama de amostra. 


\section{ANÁLISE DE ATIVIDADE ANTIOXIDANTE TOTAL PELA CAPTURA DO RADICAL ABTS•+}

O método ABTS (ácido 2,2'-azino-bis 3-etilbenzotiazolin 6-ácido sulfônico) foi utilizado como descrito por Rufino et al. (2007), O radical ABTS •+ é formado por uma reação química com persulfato de potássio. Então, o radical ABTS ${ }^{\bullet+}$ é diluído em etanol até obter uma medida de absorbância de 0,70 ( \pm 0,02 ) a um comprimento de onda de $734 \mathrm{~nm}$. Alíquotas com três diferentes volumes em triplicata das amostras reagiram com o radical $\mathrm{ABTS}^{\bullet+}$ por $6 \mathrm{~min}$. Uma curva padrão com soluções de Trolox e a atividade antioxidante foi expressa em $\mu \mathrm{mol}$ equivalente de trolox por grama de amostra.

\section{ENSAIO ORAC}

Este método, mede a capacidade do antioxidante em sequestrar radicais peroxil que foram gerados por uma fonte radicalar, AAPH (2,2'-azobis(2-amidinopropano) dihidroclorado), a 37으. O radical peroxil, gerado pela reação do com oxigênio atmosférico, reage com a fluoresceína para formar um produto não fluorescente, que pode ser medido por espectrofotometria com máxima emissão de fluorescência em $575 \mathrm{~nm}$ e $578 \mathrm{~nm}$. Concentrações conhecidas de trolox foram usadas para gerar uma curva padrão. A atividade antioxidante das substâncias foi determinada através da diferença entre a área abaixo da curva (AUC) da amostra subtraída pela AUC do branco, medida pelo decaimento da fluorescência com a adição da substância antioxidante no decorrer do tempo. Este ensaio expressa o resultado em $\mu \mathrm{mol}$ de trolox equivalentes.

\section{ANÁLISE ESTATÍSTICA}

A análise estatística dos dados obtidos foi realizada em excel e no Programa Graph Pad Prism 5.0. Foi feito o teste de variância (ANOVA) com pós-teste de Tukey para comparação de médias, ao nível de significância de $5 \%$.

\section{RESULTADOS E DISCUSSÃO}

A extração é um dos processos mais utilizados para obtenção de compostos bioativos, onde um solvente age na estrutura celular do vegetal, retirando o composto de interesse. Entre os métodos mais comuns de extração, estão a maceração e percolação (extração convencional) e as metodologias consideradas como não-convencionais, como a assistida por ultrassom (US), líquido pressurizado (PLE) e fluido supercrítico (SFE). A técnica de extração utilizada foi a extração por fluído supercrítico por apresentar vantagens em relação às técnicas de extração convencionais, como menor degradação 
dos compostos e não gerar resíduos tóxicos. A figura 1 representa os extratos finais obtidos dos diferentes níveis de torra.

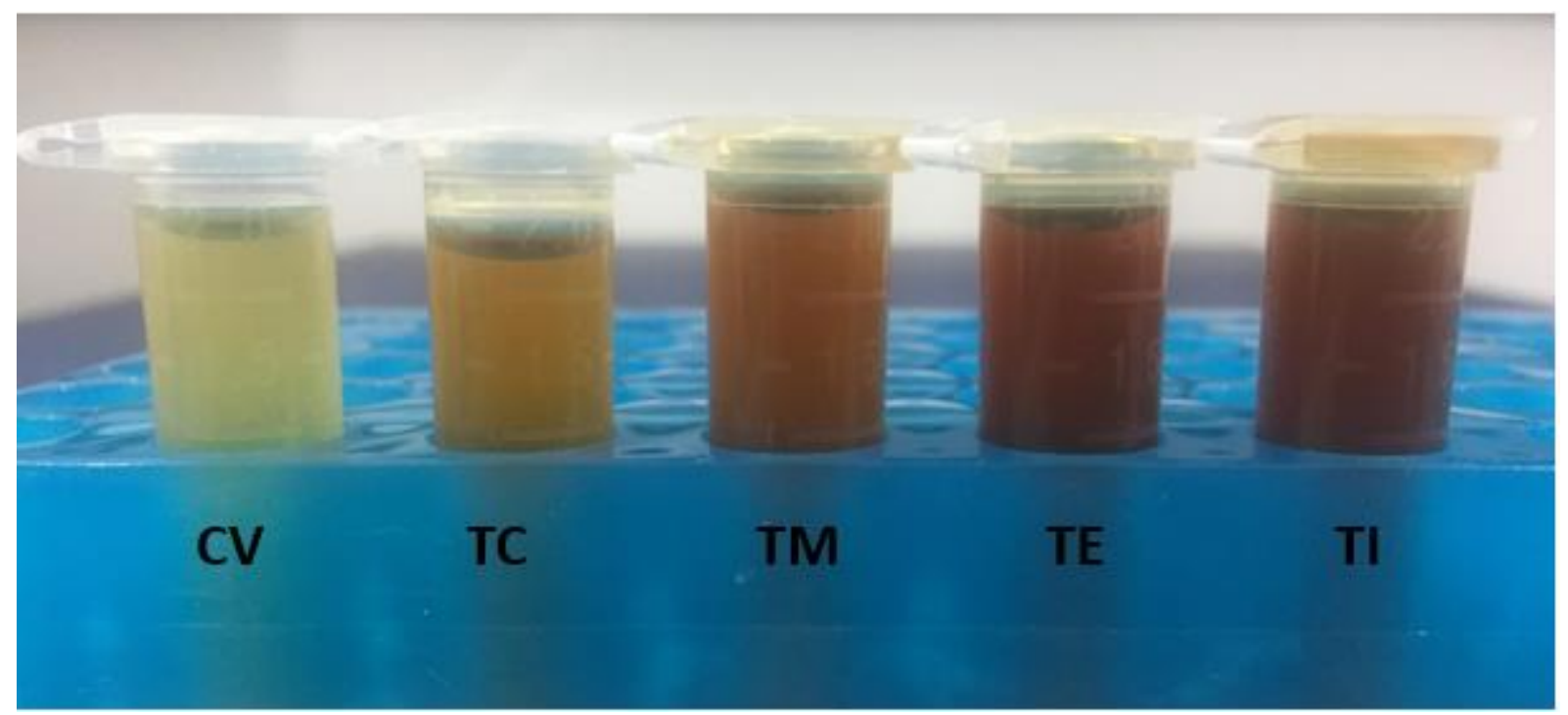

Figura 1. Amostras de café arábica extraídas por fluido supercrítico. Legenda: CV: café verde, TC: torra clara, TM: torra média, TE: torra escura e TI: torra italiana.

Existem diversos ensaios para avaliar a atividade antioxidante de substâncias biologicamente ativas, envolvendo desde ensaios químicos com substratos lipídicos a ensaios mais complexos utilizando as mais diversas técnicas instrumentais. Estes testes têm se tornado ferramentas usuais e extremamente necessárias na seleção inicial de substâncias que possam ser utilizadas como substâncias bioativas (CID; DE PEÑA, 2016). Devido aos diferentes tipos de radicais livres e as suas diferentes formas de atuação nos organismos vivos, dificilmente existirá um método simples e universal pelo qual a atividade antioxidante possa ser medida precisa e quantitativamente, sendo assim, a atividade antioxidante foi avaliada por diferentes métodos, entre eles DPPH, ABTS, FRAP, e ORAC (Figura 2).

As análises dos extratos de café pelos métodos da captura do radical ABTS e DPPH apresentaram maior potencial antioxidante quando comparado ao ensaio ORAC, onde foi observado o menor potencial antioxidante. Esse é um método mais direto do que os outros métodos, pois ocorre indução da formação de peróxido, que é instável e é formado no organismo, ao contrário dos outros radicais livres (DPPH e ABTS), que são sintéticos e instáveis, sendo considerado por muitos autores, o método que seria mais comparável ao que ocorre no organismo.

Ao comparar a capacidade antioxidante do café nos diferentes níveis de torra, pode-se observar uma mesma tendência dos resultados entre os métodos utilizados (Figura 2). No geral, a atividade antioxidante do extrato de café verde foi maior quando comparada aos demais níveis de torra, com diminuição de acordo com o maior grau de torrefação. No método de captura do radical $\mathrm{ABTS}^{+}$não foi 
observada diferença estatística $(p>0,05)$ entre os extratos de café verde e torra clara. Essa redução da atividade antioxidante observada de acordo com o grau de torrefação está de acordo com os resultados descritos em outros trabalhos que observaram o mesmo efeito (DEL CASTILLO; AMES; GORDON, 2002; DUARTE et al., 2005; HEČIMOVIĆ et al., 2011; LIANG et al., 2016).
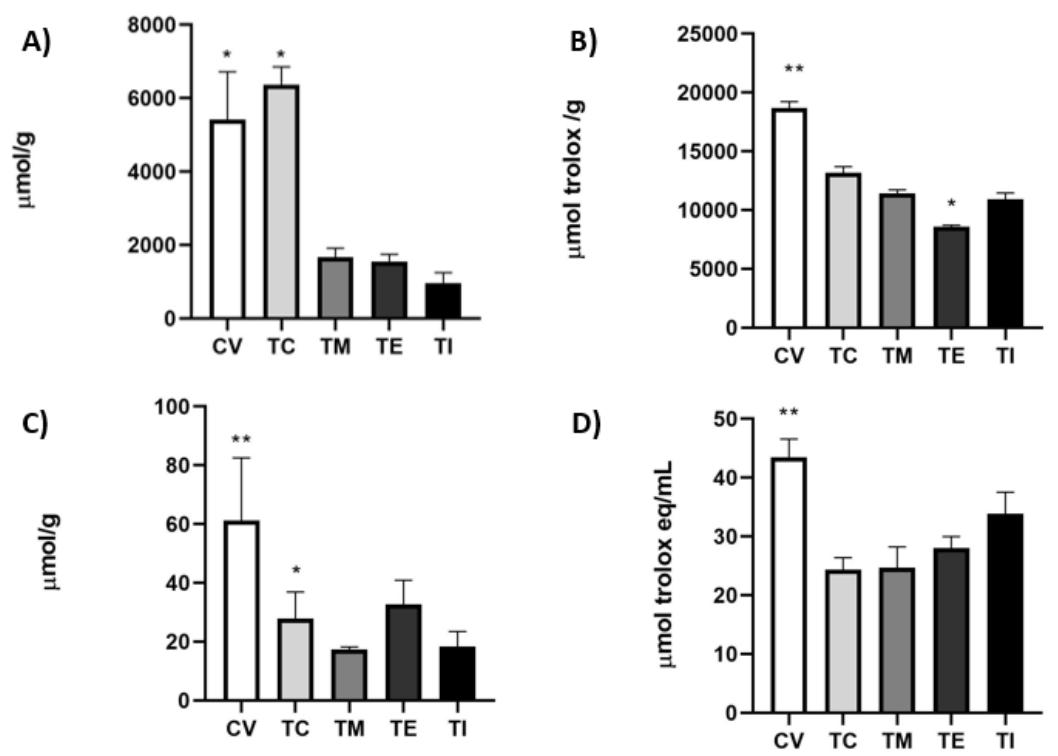

Figura 2. Capacidade antioxidante de extratos de café arábica em diferentes níveis de torra pelos métodos ABTS(A), DPPH(B), FRAP (C) e ORAD (D). Legenda: CV: café verde, TC: torra clara, TM: torra média, TE: torra escura e TI: torra italiana. Os resultados estão expressos como média \pm desvio padrão. Asteriscos representam diferença significativa. Os resultados foram comparados pelo teste One-way ANOVA, com pós-teste de Tukey $(p<0,05)$.

O processo de torrefação dos grãos de café reduziu significativamente o teor de compostos fenólicos totais (Figura 3), com redução significativa $(p<0,05)$ do extrato de café verde em comparação à torra clara, seguida de nova redução após o aumento da temperatura de torrefação $(p<0,05)$. Não houve diferença estatística $(p>0,05)$ entre os extratos de café das torras média, escura e italiana.

Os dados Tabela 1 indicam que o teor de ácido 5-cafeoilquínico (5-CQA) reduziu significativamente $(p<0,05)$ do extrato café verde para a torra clara, com seguidas reduções com aumento da temperatura de torrefação. Esse resultado está em concordância com a literatura, pois já foi observado que o 5-CQA é mais termolábil do que os seus isômeros (3-CQA e 4-CQA) (KAMIYAMA et al., 2015). A degradação do 5-CQA, que é o composto fenólico em maior abundância no café verde, pode explicar a redução da atividade antioxidante observada e a redução no teor de compostos fenólicos. 


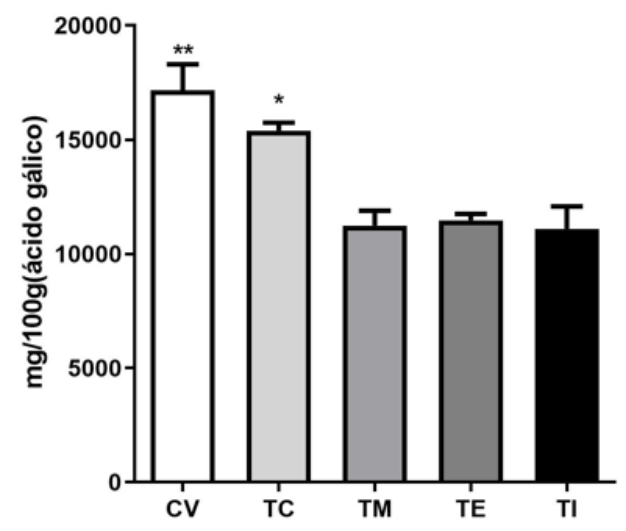

Figura 3. Teor de compostos fenólicos totais dos extratos de café arábica em diferentes níveis de torra extraídos por fluido supercrítico. Legenda: CV: café verde, TC: torra clara, TM: torra média, TE: torra escura e TI: torra italiana. Os resultados estão expressos como média \pm desvio padrão. Os resultados foram comparados pelo teste One-way ANOVA, com pós-teste de Tukey $\left({ }^{*} p<0,05,{ }^{* *} p<0,01\right)$.

Tabela 1. Teores de cafeína e 5-CQA nos extratos de café arábica em diferentes níveis de torra

\begin{tabular}{ccc} 
Extratos & $\begin{array}{c}\text { Cafeína } \\
\mathbf{m g} / \mathbf{m l}\end{array}$ & 5-CQA mg/mL \\
\hline Café verde & 80 & 19,37 \\
Torra clara & 59,4 & 4,35 \\
Torra média & 57,4 & 0,72 \\
Torra escura & 69 & 0,28 \\
\hline
\end{tabular}

Existem diversos compostos nitrogenados não proteicos no grão de café cru, tais como cafeína, teofilina, teobromina e trigonelina. De todos eles, o mais estudado é a cafeína (DÚRAN, 2017). O café possui de 1 a 2,5\% de cafeína, que é o componente mais conhecido por seus efeitos estimulantes sobre o sistema nervoso central, e geralmente é associada a uma melhora no estado de alerta, na capacidade de aprendizado e resistência ao esforço físico (GROSSO et al., 2017). O teor de cafeína não foi tão afetado pela torra quanto o de ácido clorogênico (Tabela 1).

\section{CONCLUSÃO}

Os extratos de café analisados apresentaram elevada capacidade antioxidante, independentemente do nível de torrefação, no entanto, os extratos de café verde e da torra clara apresentaram maior atividade antioxidante em comparação com as torras média, escura e italiana. $\mathrm{O}$ ácido clorogênico e os compostos fenólicos totais foram degradados durante o processo de torrefação. Os dados aqui apresentados sugerem o uso potencial do extrato aquoso de café verde e de torra clara como potencialmente benéficos à saúde. 


\section{REFERÊNCIAS}

BRAND-WILLIAMS, Wendy; CUVELIER, Marie-Elisabeth; BERSET, C. L. W. T. Use of a free radical method to evaluate antioxidant activity. LWT-Food science and Technology, v. 28, n. 1, p. 25-30, 1995.

CID, M. C.; DE PEÑA, M.-P. Coffee: Analysis and Composition. Encyclopedia of Food and Health, p. 225231, 2016.

CONAB Acompanhamento da Safra Brasileira de Café, Safra 2018, 2018. Disponível em: < https://www.conab.gov.br/info-agro/safras/cafe >. Acesso em 13 jun. 2020.

DEL CASTILLO, M. D.; AMES, J. M.; GORDON, M. H. Effect of roasting on the antioxidant activity of coffee brews. Journal of agricultural and food chemistry, v. 50, n. 13, p. 3698-703, 2002.

DÍAZ, Félix O.; ORMAZA, Angela M.; ROJANO, Benjamín A. Efecto de la Tostión del Café (Coffea arabica L. var. Castillo) sobre el Perfil de Taza, Contenido de Compuestos Antioxidantes y la Actividad Antioxidante. Información tecnológica, v. 29, n. 4, p. 31-42, 2018.

DUARTE, S. M. DA S. et al. Effect of processing and roasting on the antioxidant activity of coffee brews. Ciência e Tecnologia de Alimentos, v. 25, n. 2, p. 387-393, 2005.

DURAN, C. A. A. et al. Coffee: General Aspects and its Use beyond Drink. Revista Virtual De Quimica, v. 9, n. 1, p. 107-134, 2017.

FARAH, A. DEPAULIS; TRUGO, T.; LC, MARTIN. PR Formation of Chlorogenic Acids Lactones in Roasted Coffee. Journal of Agricultural and Food Chemistry, v. 53, p. 1105-1113, 2005.

FARAH, A. et al. Correlation between cup quality and chemical attributes of Brazilian coffee. Food Chemistry, v. 98, n. 2, p. 373-380, 2006.

CHU, Yi-Fang (Ed.). Coffee: emerging health effects and disease prevention. John Wiley \& Sons, 2012.

GROSSO, Giuseppe et al. Coffee, caffeine, and health outcomes: an umbrella review. Annual review of nutrition, v. 37, p. 131-156, 2017.

HEČIMOVIĆ, I. et al. Comparative study of polyphenols and caffeine in different coffee varieties affected by the degree of roasting. Food Chemistry, v. 129, n. 3, p. 991-1000, 2011.

JIMÉNEZ-ZAMORA, Ana; PASTORIZA, Silvia; RUFIÁN-HENARES, José A. Revalorization of coffee byproducts. Prebiotic, antimicrobial and antioxidant properties. LWT-Food Science and Technology, v. 61, n. 1, p. 12-18, 2015.

JUNG, Soohan et al. Cellular antioxidant and anti-inflammatory effects of coffee extracts with different roasting levels. Journal of medicinal food, v. 20, n. 6, p. 626-635, 2017.

KAMIYAMA, M. et al. Role of Degradation Products of Chlorogenic Acid in the Antioxidant Activity of Roasted Coffee. Journal of Agricultural and Food Chemistry, v. 63, n. 7, p. 1996-2005, 25 fev. 2015.

LIANG, N. et al. Interactions between major chlorogenic acid isomers and chemical changes in coffee brew that affect antioxidant activities. Food Chemistry, v. 213, 2016. 
FENG, Jue et al. Potent Antioxidative Activity of Unripe Fruits of Garcinia mangostana L. Natural medicines, v. 58, n. 4, p. 156-159, 2004.

NUNES, F.M. and COIMBRA, M.A., Chemical characterization of the high molecular weight material extracted with hot water from green and roasted arabica coffee. Journal of Agricultural and Food Chemistry, 2001, 49(4), 1773-1782.

PORTO, A. C. V. et al. Estimated Acrylamide Intake from Coffee Consumption in Latin America. American Journal of Agricultural and Biological Sciences, 10(2), 91, 2015.

RABELO, Mariane Helena Sances et al. Sistema CIEL* a* $b^{*}$ e CIEL* $c^{*} h^{\circ}$ : Avaliação da relação com o sistema de disco Agtron/SCAA. 2015.

RUFINO, M. D. S. M. et al. Metodologia científica: determinação da atividade antioxidante total em frutas pelo método de redução do ferro (FRAP). Embrapa Agroindústria Tropical-Comunicado Técnico (INFOTECA-E), 2006.

RUFINO, M. D. S. M. et al. Metodologia científica: determinação da atividade antioxidante total em frutas pela captura do radical livre DPPH. Embrapa Agroindústria Tropical-Comunicado Técnico (INFOTECA-E), 2007.

SINGLETON, Vernon L.; ROSSI, Joseph A. Colorimetry of total phenolics with phosphomolybdicphosphotungstic acid reagents. American journal of Enology and Viticulture, v. 16, n. 3, p. 144-158, 1965.

TRUGO, Luiz C.; MACRAE, Robert. Chlorogenic acid composition of instant coffees. Analyst, v. 109, n. 3, p. 263-266, 1984.

ZETZL, C.; BRUNNER, G.; MEIRELES, M. A. A. Standardized low-cost batch SFE-units for university education and comparative research. In: Proceedings of the 6th International Symposium on Supercritical Fluids. Versailles, 2003. p. 577-581. 